\title{
Análise das propriedades mecânicas e biológicas do cimento ósseo de fosfato de cálcio bifásico nanoestruturado de cura rápida
}

\author{
Analysis of mechanical and biological properties \\ of fast setting time nanostructured biphasic calcium \\ phosphate bone cement
}

\author{
Marcelo Augusto Brito Madureira ${ }^{1}$, Katia Michelle Freitas ${ }^{2}$, \\ Camila de Lima Cruz ${ }^{2}$, Tércio Assunção Pedrosa ${ }^{3}$, Rafael Lopes ${ }^{3}$, \\ Sidney Nicodemos da Silva ${ }^{2}$, Danielle Marra de Freitas Silva Azevedo ${ }^{2}$
}

\begin{abstract}
${ }^{1}$ Laboratório de Biomateriais - Pós-Graduação em Engenharia de Materiais - Centro Federal de Educação Tecnológica de Minas Gerais - POSMAT/CEFET-MG, CEP: 30421-169, Belo Horizonte, Minas Gerais, Brasil

${ }^{2}$ Centro Federal de Educação Tecnológica de Minas Gerais - Pós-Graduação em Engenharia de Materiais, POSMAT/CEFET-MG, CEP: 30421-169, Belo Horizonte, Minas Gerais, Brasil

${ }^{3}$ Centro de Desenvolvimento da Tecnologia Nuclear - CDTN/CNEN, CEP: 31270-901, Belo Horizonte, Minas Gerais, Brasil

e-mail: marcelobrito.mec@gmail.com,artemisk_farma@yahoo.com.br, camilalc98@hotmail.com, sidneynicodemos@yahoo.com.br, daniellemarra@cefetmg.br.tap@cdtn.br, labmev.cdtn@gmail.com, rafaellopes1984@yahoo.com.br
\end{abstract}

\section{RESUMO}

Nas últimas duas décadas intensificaram-se os estudos para desenvolvimento de novas terapêuticas para aplicações em doenças degenerativas do tecido ósseo, bem como formas menos invasivas de tratamentos de traumas de acidentes viários. Neste cenário, biocimentos de fosfato de cálcio (CFCs) de cura rápida para aplicações injetáveis e/ou moldáveis, permitem o uso através de técnicas cirúrgicas minimamente invasivas. Matrizes de CFCs têm atraído grande interesse para uso em ortopedia e odontologia como substitutos para partes danificadas do sistema osteocondral, permitindo sua utilização na reparação ou preenchimento ósseo. Neste trabalho foram processados CFCs constituídos por dois diferentes fosfatos de cálcio bifásicos (BCP), um com distribuição micrométrica e outro com distribuição nanométrica, fosfato de sódio e carboximetilcelulose, visando a utilização deste material em procedimentos cirúrgicos. As matérias primas foram caracterizadas físico-quimicamente por difração de raio X, microscopia eletrônica de varredura acoplada com espectroscopia de energia dispersiva de raios X. O tempo de pega do material foi avaliado pelo ensaio de Vicat e a resistência mecânica do CFC foi avaliada através dos ensaios de Flexão (resistência mecânica a tração) e U1tramicrodureza (módulo de elasticidade). As propriedades biológicas foram avaliadas através dos ensaios in vitro de degradação em solução Tris-HCL e citotoxicidade em cultura de bactérias e ensaio in vivo pelo método de HET-CAM. Os resultados mostraram um melhor desempenho do BCP nanométrico, tendo tempo de pega final baixo, 22 minutos, e resistência mecânica da ordem de $4 \mathrm{MPa}$, compatível com a expectativa esperada para osso esponjoso. Os ensaios biológicos confirmaram a resposta biológica satisfatória destes nanocompósitos. Isso demonstra que o material tem potencial para aplicação clínica em substituição ao cimento acrílico hoje largamente utilizado.

Palavras-chave: Cimento ósseo, Fosfato de cálcio bifásico, tempo de pega, resistência mecânica.

\section{ABSTRACT}

Over the past two decades, the development of new therapies for applications in degenerative bone tissue diseases has intensified, as well as less invasive forms of road accident trauma treatment. In this scenario, fast setting time calcium phosphate bone cement (CFCs) for injectable and/or moldable applications allows for use through minimally invasive surgical techniques. CFC arrays have attracted great interest for use in orthopedics and dentistry as substitutes for damaged parts of the osteochondral system, allowing their use in bone repair or filling. In this work, CFCs consisting of two different biphasic calcium phosphates (BCP) were processed, one with micrometric distribution and the other with nanometric distribution, sodium phosphate and carboxymethylcellulose, aiming at the use of this material in surgical procedures. The raw materials were 
physically and chemically characterized by X-ray diffraction, scanning electron microscopy coupled with Xray dispersive energy spectroscopy. The setting time of the material was evaluated by Vicat tests and the mechanical strength of the CFC was evaluated through the flexural tests (tensile strength), ultramicrohardness (modulus of elasticity). Biological properties were evaluated by in vitro Tris-HCL degradation assay, cytotoxicity assay by bacterial culture and in vivo assay by the HET-CAM method. The results showed a better performance of the nanometer CFC, having a low final setting time, 22 minutes, and mechanical strength of 4 $\mathrm{MPa}$, compatible with the expected expectation for cancellous bone. Biological assays confirmed the satisfactory biological response of these nanocomposites. This demonstrates that the material has potential for clinical application in place of the widely used acrylic cement.

Keywords: Bone cement, Biphasic calcium phosphate, Setting time, Mechanical strength.

\section{INTRODUÇÃO}

Os compostos cerâmicos de fosfato de cálcio são estudados há cerca de um século como materiais de substituição óssea. Porém, a partir do início dos anos 80, com o desenvolvimento dos cimentos de fosfato de cálcio (CFC), o seu potencial clínico aumentou [1]. O crescente interesse pelos CFCs aconteceu devido a sua semelhança química com a matriz óssea dos mamíferos e se ampliou por serem materiais que podem ser moldados e apresentarem capacidade de endurecimento in situ, proporcionando estabilidade [2]. Além disso, os CFCs apresentam elevada biocompatibilidade, além de suas razoáveis propriedades bioativas e osteocondutoras são potencialmente reabsorvíveis - promovendo uma remodelação da matriz óssea natural. As principais características ou vantagens dos CFCs devem-se ao fato de apresentarem boa molhabilidade, elevado potencial de hidratação, capacidade de endurecimento quando aplicados em meios biológicos, além disso, podem ser usados como carreadores medicamentosos $[3,4]$.

Segundo GINEBRA e MONTUFAR [5] o principal uso dos CFCs está nas aplicações de regeneração óssea, como reconstrução maxilofacial e craniofacial, tratamento de ossos fraturados, preenchimento de defeitos ósseos criados cirurgicamente ou traumaticamente e para o tratamento de fraturas vertebrais e vertebroplastias. Além disso, há estudos com a utilização do CFC em sistemas de liberação de medicamentos, scaffolds e pastas moldáveis em aplicações médicas e odontológicas [6, 7]. Apesar disso, o seu uso é ligado a locais com baixa solicitação mecânica, visto que o alto módulo de elasticidade, baixa tenacidade a fratura com um comportamento frágil dos biocimentos de fosfato de cálcio são as principais desvantagens deste tipo de material [8].

O tempo de pega dos CFCs é um índice importante para avaliar o desempenho do CPC. O tempo de pega apropriado não apenas ajuda a operação clínica do médico, mas também alivia a dor dos pacientes [9]. Esse tempo deve ser lento o suficiente para permitir que o cirurgião processe a pasta cimentícia e faça o implante, porém rápido o bastante para evitar atrasos na operação, pois deformações durante o tempo de cura podem levar a rachaduras no cimento implantado [7].

Os CFCs idealmente precisam apresentar propriedades mecânicas semelhantes às do tecido ósseo onde o CFC será usado como material de reparação [10] e tempo de pega entre 8 e 15 minutos [11]. O presente estudo teve como objetivo de processar um cimento ósseo de fosfato de cálcio bifásico com tempo de cura, propriedades mecânicas e biológicas adequadas ao uso biomédico.

\section{MATERIAIS E MÉTODOS}

\subsection{Materiais}

Os dois diferentes fosfatos de cálcio bifásico (BCP), um com distribuição de tamanho de partículas micromé-

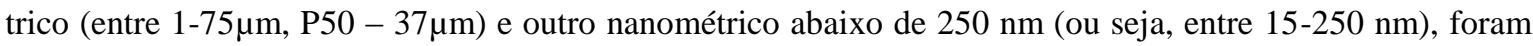
ambos fornecidos pela empresa Phosther Tecnologia de Aglomerações Ltda. O material é composto majoritariamente de duas fases, uma cristalina e outra amorfa - contendo a hidroxiapatita (HA) com cerca de $69 \%$ e o Fosfato de Cálcio Amorfo (ACP) com cerca de $31 \% \mathrm{~m} / \mathrm{m}$. A carboximetilcelulose (CMC), empregada como ligante, foi fornecida pela empresa DENVER - Cotia/SP, para formulação do compósito na forma de pó; suas características físico químicas são: grau de pureza de $99,84 \%$, grau de substituição 0,8 , teor de umidade de 6,1 (in natura), $\mathrm{pH}$ 7,0 e viscosidade de $430 \mathrm{cP}$, sendo estas características avaliadas segundo procedimentos da norma ASTM D 1439 e método de Brookfield. O Fosfato de Sódio (FS) usado no estudo foi o fosfato de sódio bibásico heptahidratado - $\mathrm{Na}_{2} \mathrm{HPO}_{4} \cdot 7 \mathrm{H}_{2} \mathrm{O}$ - grau P.A. fornecido pela empresa Dinâmica Química Contemporânea LTDA, esse componente foi usado na forma de solução aquosa aceleradora de cura do (CFC). 


\subsection{Métodos}

\subsubsection{Processamento do cimento de fosfato de cálcio}

O processamento do CFC foi conduzido através das misturas entre fosfato de cálcio bifásico (BCP), na forma micrométrica ou nanométrica, e carboximetilcelulose (CMC) na proporção de 3,2\% $\mathrm{m} / \mathrm{m}$. Os pós foram misturados manualmente por 3 min em béquer de vidro com uso de um bastão de vidro, em bateladas de $10 \mathrm{~g}$.

\subsubsection{Solução aceleradora}

A solução aceleradora de cura formulada consistiu numa diluição de fosfato de sódio (FS) [12]. Neste estudo foi utilizada a concentração de 5\% de FS, preparada através da diluição de $10 \mathrm{~g}$ de $\mathrm{Na}_{2} \mathrm{HPO}_{4} \cdot 7 \mathrm{H}_{2} \mathrm{O}$ em $100 \mathrm{~mL}$ de água destilada. Estes cálculos estequiométricos levaram em consideração a presença da água ligada ao FS.

\subsubsection{Processamento da pasta de cimento ósseo e corpos de prova}

O processamento da pasta cimentícia seguiu o fluxograma da Figura 1. Foram processados 2 grupos de material, um BCP com distribuição de tamanho de partículas micrométrico e outro nanométrico.

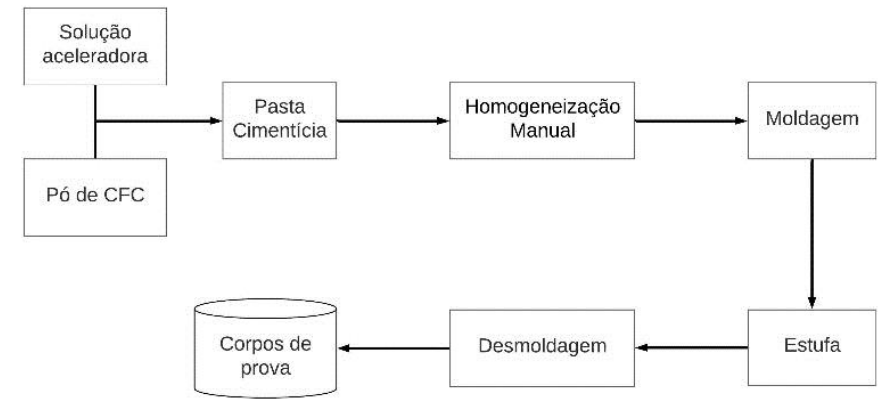

Figura 1: Fluxograma do processamento do CFC.

Após a formação dos pós de CFC, procedeu-se com a incorporação da solução aceleradora, na proporção de $0,8 \mathrm{~mL} / \mathrm{g}$ de pó de CFC e homogeneização manual por 3 minutos com auxílio de uma espátula de metal para formação da pasta de CFC; em seguida, a pasta foi depositada nos moldes que seguiram para a estufa a $(37 \pm 3){ }^{\circ} \mathrm{C}$ por 24 horas $[13,14]$. Depois de retirados da estufa os corpos de prova foram desmoldados e encaminhados para os ensaios e caracterizações.

\subsubsection{Microscopia eletrônica de varredura (MEV) e a espectrometria de energia dispersiva de raios $X$ (EDS)}

As análises foram realizadas em um microscópio MEV acoplado com EDS marca Shimadzu, modelo Superscan SSX - 550 e outro MEV de maior resolução lateral (da ordem de 0,5 nm), com emissão por efeito de campo (FEG-MEV), modelo SIGMA VP, fabricado pela Carl Zeiss Microscopy com coluna GEMINI@ com EDS modelo XFlash 410-M - Bruker Nano GmbH. Em ambas microscopias as amostras foram aspergidas sobre fitas de carbono e em seguida metalizadas com ouro. As amostras foram observadas com detector de elétrons secundários (SE), operados com tensão entre 5 a $15 \mathrm{kV}$. A microscopia eletrônica de varredura (MEV) e a espectrometria de energia dispersiva de raios X (EDS) foram utilizadas com a finalidade de visualização da topografia (microestrutura) e a realização da análise química elementar semi qualitativa dos pós de CFC.

\subsubsection{Difração de Raios X (DRX)}

A caracterização de DRX foi realizada em difratômetro de raios-X automático, marca Rigaku, modelo DMAX, com goniômetro $\theta-\theta$, gerador de raios-X de $3 \mathrm{~kW}$ de alta frequência e câmara de alta temperatura. $O$ ensaio foi realizado à temperatura ambiente. As difrações obtidas foram comparadas com a base de dados ICDD (International Center for Diffration Data) para identificação das fases. A Difratometria de Raio X (DRX) foi utilizada na caracterização dos pós de CFC com o objetivo de se determinar as estruturas cristalinas nas amostras. 


\subsubsection{Ensaio de tempo de pega}

Os ensaios para determinação dos tempos de pega inicial e final das pastas de CFC foram realizados com o uso do aparelho de Vicat e tendo como base os trabalhos de JIA et. al [15], BAUDÍN et. al [16] e da norma ABNT NBR 12128. Os corpos de prova foram preparados em moldes poliméricos de dimensões $\varnothing 15 \mathrm{~mm} \mathrm{x}$ $10 \mathrm{~mm}$, como apresentado na Figura 2, onde a pasta cimentícia foi depositada e depois levada à estufa a temperatura de $38^{\circ} \mathrm{C}$.

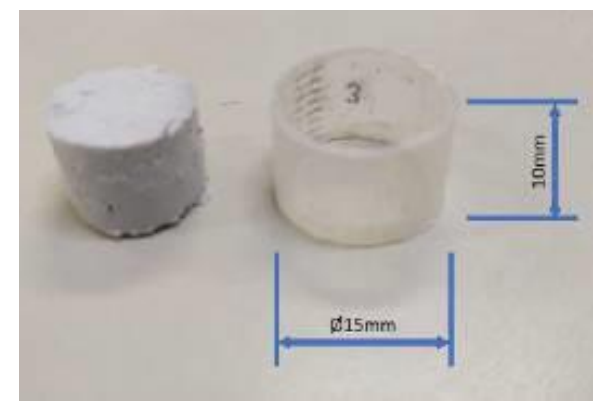

Figura 2: a) Aspecto corpo de prova para tempo de pega, b) Molde utilizado preparação dos CPs.

A cada 5 minutos uma amostra foi retirada da estufa e submetida ao ensaio. O tempo inicial correspondeu ao tempo, em minutos, decorrido desde a introdução dos corpos de prova na estufa até o momento em que a pasta cimentícia apresentou resistência evidente à penetração da agulha. O tempo final foi determinado quando a agulha não conseguiu penetrar o material. O valor médio do tempo inicial e final de pega para cada grupo amostral foi calculado e os resultados representados pela média mais desvio padrão. O grupo amostral com menor tempo de pega foi submetido a ensaios mecânicos e biológicos.

\subsubsection{Ensaios de Flexão a três pontos}

Os ensaios de flexão a três pontos, com objetivo de avaliar a resistência do material a tração na flexão, foram realizados na máquina universal de ensaios SHIMADZU, modelo AG-X, com célula de carga 10kN e sistema de controle e aquisição de Trapezium Lite X. A máquina foi preparada com distância de 30mm entre os dois apoios cilíndricos utilizados e a carga foi aplicada verticalmente no centro do corpo de prova à velocidade de descida de $1 \mathrm{~mm} / \mathrm{min}$ [9]. Os corpos de prova foram confeccionados com 6,00 x 6,00 x 40,00 mm (largura x espessura x comprimento) e, antes de serem usados no ensaio, passaram por uma inspeção visual a fim de evitar o uso de corpos de prova com rachaduras aparentes.

A norma ASTM C1161 - 18 [17], bem como os trabalhos de BERTOL et. al [18] e de BOEHM et. al [19] foram usados como referência na condução do ensaio. O cálculo da tração na flexão foi realizado através da equação (1):

$$
\mathrm{S}=3 \mathrm{PL} / 2 \mathrm{bd} \mathrm{d}^{2}
$$

Onde: S é a tração na flexão em mega pascal (MPa), P é a carga aplicada em Newtons (N), L é a distância em milímetros (mm) entre os apoios, b é altura e d é a espessura do corpo de prova, ambos em milímetros.

\subsubsection{Ensaio de Ultramicrodureza}

Os ensaios de ultra microdureza realizados em equipamentos dinâmicos de ensaio de dureza são capazes de fornecer o módulo de elasticidade, além da ultramicrodureza. Isso é possível pois o equipamento aplica progressivamente a carga escolhida e faz a sua medição simultaneamente aos deslocamentos realizados pelo penetrador. Assim, o software do equipamento constrói a curva de carga e deformação e fornece a ultramicrodureza e o módulo de elasticidade do material ensaiado [20].

Utilizou-se um ultramicrodurômetro da marca SHIMADZU, modelo DUH-211S, com carga de $3 \mathrm{mN}$, com tempo de indentação e de descarga de 15 segundos. Os corpos de prova foram confeccionados com 6,00 x 6,00 x 20,00 mm (largura x espessura x comprimento), sendo realizadas 3 (três) leituras na superfície de cada amostra. 


\subsubsection{Ensaio de citotoxicidade/viabilidade}

Para avaliação da citotoxicidade/viabilidade, as amostras de biocimentos foram submetidas ao ensaio de cultura de bactérias através do teste resazurina. As cepas utilizadas foram: Escherichia coli (E.coli, ATCC 11229) e Staphylococcus aureus (S. aureus, ATCC 6538). As amostras foram esterilizadas por irradiação gama a $25 \mathrm{KGy}$.

As massas das amostras foram mensuradas e utilizou-se $0,2 \mathrm{~g}$ do biocimento para cada $1 \mathrm{~mL}$ do solvente extrator (caldo nutriente) por $24 \mathrm{~h}$ em estufa à $37^{\circ} \mathrm{C}$. Após isso, $1 \mathrm{~mL}$ dos extratos de cada amostra foram colocados em tubos com suspensão microbiana, equivalente à 5 x $105 \mathrm{UFC/mL}$, obtidas do procedimento de suspensão direta de colônias em ágar. Os controles positivos também foram utilizados conforme o tipo de cepa testada, além do controle negativo com salina $0.9 \%$. As amostras e controles foram mantidos em estufa durante $24 \mathrm{~h}$ à $37^{\circ} \mathrm{C}$; posteriormente, 5 microlitros da solução de resazurina $(280 \mu \mathrm{g} / \mathrm{mL})$ foi adicionada em cada por $3 \mathrm{~h}$ à $37^{\circ} \mathrm{C}$. A resazurina é um indicador colorimétrico com a propriedade redox em que a forma oxidada é azul (célula não viável) e a forma reduzida é rósea (célula viável). A absorbância foi determinada por Espectrofotômetro de Ultravioleta Visível Varian Cary 50 em dois comprimentos de onda de 570 e $600 \mathrm{~nm}$. Ensaios de citotoxicidade/viabilidade foram realizados em pelo menos quatro repetições independentes e calculadas em comparação com o controle (100\%).

\subsubsection{Ensaio in vivo HET-CAM}

A avaliação de biocompatibilidade do material foi realizada pelo método HET-CAM [21, 22]. O ensaio é baseado na análise do aparecimento de reações irritativas na membrana corioalantóide de ovos de galinha fertilizados em resposta à exposição do biomaterial proposto. Para o procedimento, foram adquiridos ovos de galinha White Leghorn comercialmente férteis, sem micoplasma e provenientes da Granja Tomolei, com certificado de qualidade. Os ovos foram colocados na incubadora, que os mantinham em rotação e sob condições controladas de temperatura $(37,8 \pm 1,0)^{\circ} \mathrm{C}$ e umidade $(50-60) \%$. No $9^{\circ}$ dia de incubação, a rotação foi suspensa e os ovos foram colocados na posição vertical, com a bolsa de ar na parte superior. No $10^{\circ}$ dia de incubação, os ovos foram retirados, colocados no ovoscópio para verificar a formação e viabilidade do embrião.

Os ovos foram abertos perto da câmera de ar com tesoura cirúrgica, revelando a membrana corioalantóide altamente vascularizada (CAM). Os implantes foram adicionados sobre a membrana, avaliados visualmente, a olho nu, e fotografias foram capturadas com uma câmera fotográfica. A superfície da CAM foi avaliada quanto ao tempo do surgimento de hiperemia, hemorragia, lise e/ou coagulação, sendo: Hiperemia: surgimento de capilares e/ou a dilatação dos vasos visíveis; Hemorragia: perda de sangue dos vasos para o meio; Coagulação: aglutinação e precipitação. Essa avaliação aconteceu em 3 períodos, 30, 120 e 300 segundos de contato entre material e a CAM. O controle irritante positivo $(\mathrm{C}+$ ) foi solução de hidróxido de sódio $0,1 \mathrm{~N}$ e para o controle negativo (C-) usou-se cloreto de sódio a $0,9 \%$ (solução salina) e para cada amostra foram utilizados 3 ovos galados. A Figura 3 ilustra o contato direto do biomaterial com a CAM do ovo embrionado de galinha.

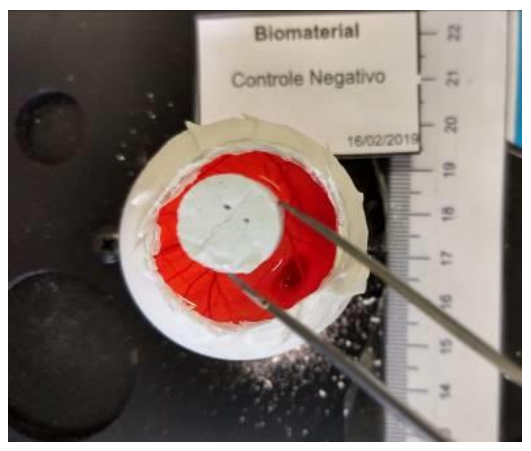

Figura 3: Imagem ilustrativa do ensaio referente ao contato direto do biomaterial com a membrana corioalantóide do ovo embrionado de galinha.

As alterações na membrana corioalantóide, conforme o tempo decorrido de contato com o biomaterial, receberam escores de acordo com a tabela 1. A classificação final dos materiais testados, em relação ao seu potencial de irritabilidade segue a escala descrita na tabela 2. A média do somatório dos escores dos ovos foi utilizada para determinar a classificação final dos biomateriais. 
Tabela 1: Tempo e escores para alterações na membrana corioalantóide

\begin{tabular}{|c|c|c|c|}
\hline \multirow{2}{*}{ FENÔMENOS } & \multicolumn{3}{|l|}{ TEMPO } \\
\hline & $\mathrm{T} \leq 30 \mathrm{~S}$ & $30 \mathrm{~S}<\mathrm{T} \leq 120 \mathrm{~S}$ & $120 \mathrm{~S}<\mathrm{T} \leq 300 \mathrm{~S}$ \\
\hline Hiperemia & 5 & 3 & 1 \\
\hline Hemorragia & 7 & 5 & 3 \\
\hline Coagulação & 9 & 7 & 5 \\
\hline
\end{tabular}

Tabela 2: Escala para classificação final quanto ao seu potencial de irritabilidade no HET-CAM

\begin{tabular}{l|l}
\hline MÉDIA DA PONTUAÇÃO & CLASSIFICAÇÃO \\
\hline 0 a 0,9 & Não irritante (NI) \\
1 a 4,9 & Irritante leve (IL) \\
5 a 8,9 & Irritante moderado (IM) \\
10 a 21 & Irritante severo (IS) \\
\hline
\end{tabular}

\subsubsection{Ensaio de degradação}

O ensaio de degradação foi realizado no Laboratório de Biomateriais e no laboratório de Química Orgânica do CEFET/MG. A degradação do material foi avaliada a partir da diferença de massa das amostras após 1, 3 e 7 dias de imersão em solução tris(hidroximetil)aminometano (Tris-HCl), conforme ISO 10993-14 [23] e estudos de SOLONENKO et al. [24], DING et al. [25] e WANG et al. [26]. Além disso, foi monitorado a mudança de pH e dosagem colorimétrica do cálcio da solução após a imersão.

Inicialmente foi preparada uma solução de Tris- $\mathrm{HCl}$, onde 13,25g de tris- $\mathrm{HCl}$ foram diluídos em 500 $\mathrm{mL}$ de água deionizada e foi realizado o ajuste de $\mathrm{pH}$ para 7,4 \pm 0.1 . Os corpos de prova foram pesados, alocados em tubos de ensaio com a solução Tris- $\mathrm{HCl}$, tampados e colocados em estufa a $37^{\circ} \mathrm{C}$. Após cada período estabelecido de ensaio, foram retiradas da estufa 3 amostras de cada grupo e secas em estufa a $68^{\circ} \mathrm{C}$ por 48h. Posteriormente, as amostras foram novamente pesadas e a perda de massa foi calculada através da Equação 2.

$$
\mathrm{W}=[(\mathrm{Wi}-\mathrm{Wf}) / \mathrm{Wi}] \times 100
$$

Sendo: $\mathrm{W}=$ diferença percentual de massa $(\%), \mathrm{Wi}=$ massa inicial em gramas $(\mathrm{g})$ e $\mathrm{Wf}=$ massa final em gramas (g). Essa equação possibilita a verificação da diferença percentual entra a massa inicial e final do material ensaiado.

A concentração de cálcio foi avaliada através da medição fotométrica de cálcio. Foi usado o sistema para a determinação do cálcio por reação de ponto final em amostras da empresa Labtest (CALCIO Liquiform ref.90-2/60 LABTEST) para detecção de absorbância de 570nm.

A determinação do pH foi realizada com o pHmetro digital. As medidas da concentração de cálcio foram realizadas utilizando kits de CALCIO Liquiform (Labtest ${ }^{\circledR}$, Lagoa Santa, Brasil) de acordo com as instruções do fabricante.

\section{RESULTADOS E DISCUSSÃO}

\subsection{Microscopia eletrônica de varredura (MEV) e a espectrometria de energia dispersiva de raios $X$ (EDS)}

Os resultados do MEV para as amostras de BCPs micrométricas e nanométricas utilizadas no processamento dos cimentos ósseos são apresentados na Figura 4 a e b. 

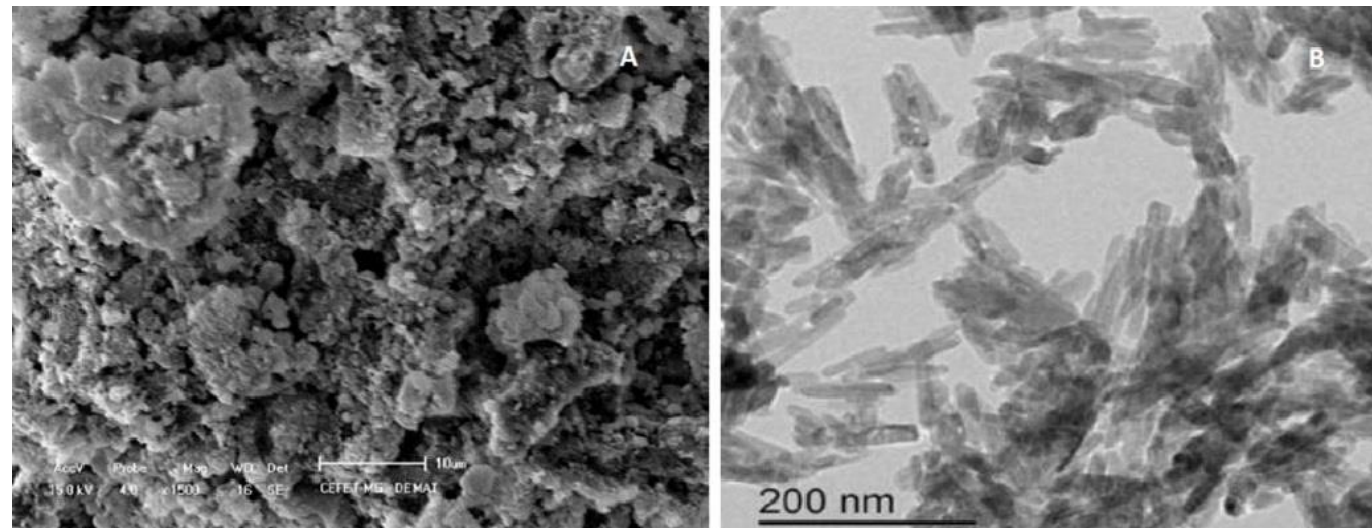

Figura 4: a) BCP micrométrico e b) BCP nanométrico

As imagens mostram aspectos morfológicos com alguns sítios de coalescência (agregação) dos cristais de fosfato de cálcio bifásico (BCP) na forma micrométrica e nanométrica. A distribuição de tamanhos medido por difração a laser do BCP mostrou que o material particulado micrométrico possui uma faixa de entre 1$75 \mu \mathrm{m}$ com $\mathrm{P}_{50}$ de $37 \mu \mathrm{m}$. Já o $\mathrm{BCP}$, constituído por particulados nanométricos, mostrou aspecto morfológico de fibras (razão de aspecto maior que 5) constatado através de medições com o MEV, apresentando a seguintes faixa de tamanhos: $40 \%$ das partículas apresentam maior dimensão abaixo de $0,1 \mu \mathrm{m}(100 \mathrm{~nm}), 73 \%$ das partículas estão abaixo de $0,15 \mu \mathrm{m}(150 \mathrm{~nm}), 95 \%$ das partículas apresentam tamanhos abaixo de $0,2 \mu \mathrm{m}$ $(200 \mathrm{~nm})$ e $100 \%$ das partículas são menores na sua maior dimensão a 0,25 $\mu \mathrm{m}(250 \mathrm{~nm})$.

Foi realizada uma varredura com espectrometria de energia dispersiva no cimento ósseo para verificação da proporção de cálcio e fosforo no material processado. Os resultados da caracterização confirmaram a presença de cálcio, fósforo com razões $\mathrm{Ca} / \mathrm{P}$ compatíveis com hidroxiapatita, uma vez que a proporção entre cálcio e fósforo do material está próxima 1,67 [27, 28].

\subsection{Difração de Raios X (DRX)}

O resultado da caracterização DRX dos corpos de prova processados de ambos os CFCs estão representados na Figura 5.

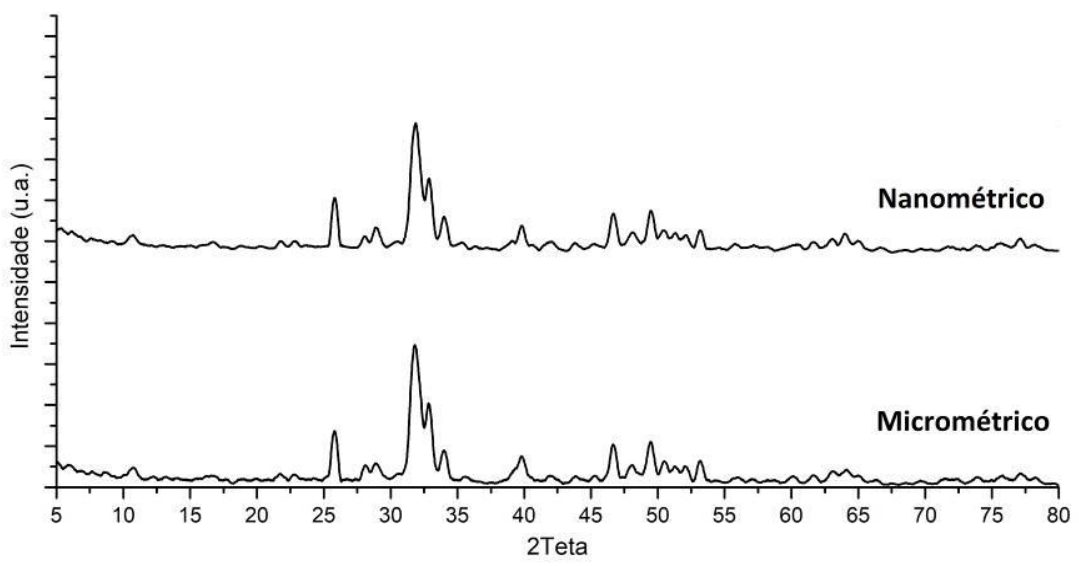

Figura 5: DRX dos CFCs processados

Os resultados do difratograma apresentaram perfil de picos identificados pelas fichas do JCPDS 9.432 (hidroxiapatita) e a fase amorfa - ACP, conforme também encontrado na literatura [29, 30]. Isso indica que não houve formação de outras fases de fosfato de cálcio ou decomposição durante o processamento do material. O percentual de CMC e FS estão ambos abaixo do limite de detecção da técnica. 


\subsection{Ensaio de tempo de pega}

Durante os ensaios de tempo de pega, notou-se que o material apresentou três comportamentos evidentes, sendo eles: ausência total de resistência a penetração da agulha de Vicat, resistência parcial à penetração da agulha (a agulha penetrou o material, porém com menos vigor), ou resistência total a penetração da agulha. Devido a esse comportamento, o tempo inicial foi definido no tempo em que a pasta cimentícia apresentou resistência evidente a penetração da agulha e o tempo final foi marcado quando a agulha não conseguiu penetrar o material. O resultado dos ensaios de pega pode ser visto Figura 6.
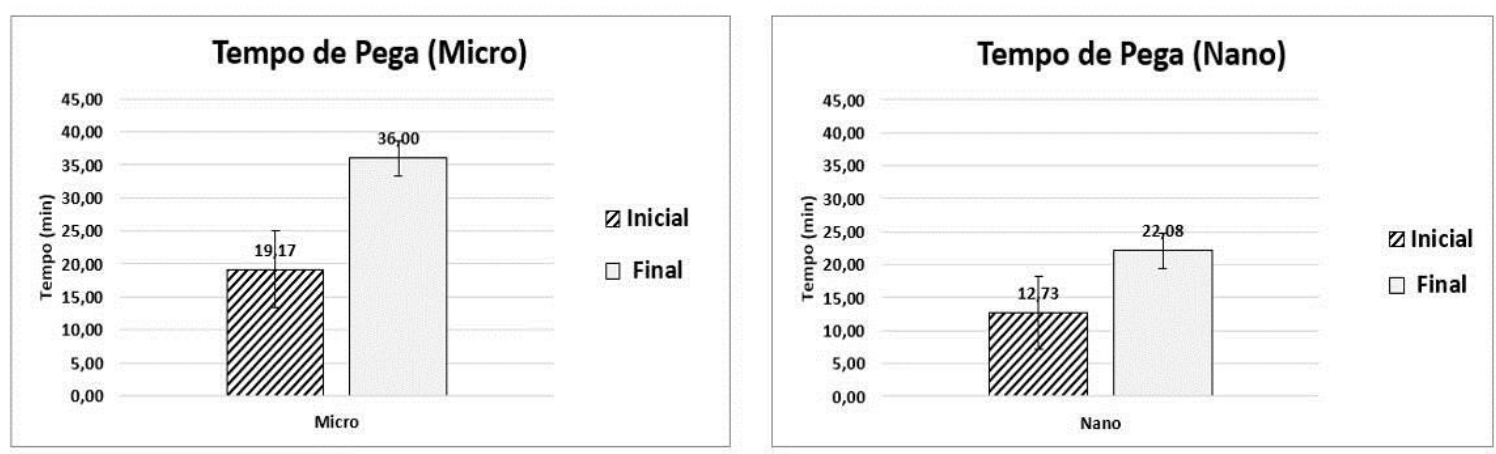

Figura 6: Tempo de pega inicial e final para o CFC micrométrico e nanométrico

O tempo de 7 minutos é o tempo médio relatado pela literatura médica para implantação de um cimento ósseo [27]. JANSEN et al. [11] detalha que um tempo inicial de cura entre 3 e 8 minutos e final de até 15 são adequados para diversos procedimentos cirúrgicos. Neste estudo, o tempo inicial de pega do CFC nanométrico foi 33,6\% menor que do CFC micrométrico, sendo da ordem de 19 minutos para CFC micrométrico e 12 minutos para o cimento nanométrico. Mesmo com essa redução, os tempos ficaram acima do adequado para a aplicação clínica. Houve também uma redução de 38,7\% no tempo final de pega, sendo por volta de 36 minutos para o CFC micrométrico e 22 minutos para o CFC nanométrico. Como o grupo amostral processado com material nanométrico apresentou menor tempo de pega, ele foi submetido aos ensaios mecânicos e biológicos.

\subsection{Ensaios mecânicos}

O grupo amostral composto pelo cimento nanométrico apresentou melhor desempenho no tempo de pega. Esse grupo foi caracterizado mecanicamente a fim de verificar sua resistência a tração na flexão (através do ensaio de flexão por 3 apoios) e seu módulo de elasticidade (através do ensaio de ultramicrodureza), conforme apresentado na Tabela 3.

Tabela 3: Resultado dos ensaios mecânicos de flexão

\begin{tabular}{l|l|l|l}
\hline ENSAIO & VALOR & DP & UNIDADE \\
\hline Flexão 3 apoios & 3,89 & 0,42 & $\mathrm{MPa}$ \\
Módulo de Elasticidade & 7,30 & 1,20 & $\mathrm{GPa}$ \\
\hline
\end{tabular}

O desempenho mecânico do osso é determinado pelo tipo e disposição de diferentes elementos estruturais. Os minerais duros contribuem para uma alta resistência e rigidez para resistir a tensões de compressão e fraturas, enquanto fibras de colágeno complacentes proporcionam alta tenacidade e viscoelasticidade para retardar a propagação da fratura sob tensão de cisalhamento ou tração [31].

Segundo a literatura a resistência a flexão e a rigidez do tecido ósseo pode ter valores diferentes para os diferentes ossos do corpo. Por isso, o osso cortical apresenta resistência a flexão entre 50 a $150 \mathrm{MPa}$ e módulo de elasticidade entre 7 e 30GPa, já o osso esponjoso tem resistência a flexão entre 1,2 e 20 MPa e módulo de elasticidade de 0,01 a $5 \mathrm{GPa}[7,10,32]$.

Neste estudo, todos os resultados dos ensaios de resistência a flexão apresentaram valores dentro da faixa de resistência do osso esponjoso, porém o módulo de elasticidade encontrado foi $46 \%$ maior que do osso esponjoso. GARCIA et al. [33] afirma que quanto maior o módulo de elasticidade do material menor 
será a deformação elástica resultante da aplicação de uma tensão. Os resultados mostram que o módulo de elasticidade do material foi maior que o esperado.

\subsection{Ensaio de citotoxicidade/viabilidade}

Neste ensaio foi utilizado o corante resazurina como indicador de viabilidade celular, a fim de avaliar a biocompatibilidade do biocimento. A redução da resazurina correlaciona-se com o número de organismos vivos, pois se comporta como substrato cromogênico de enzimas desidrogenases mitocondriais, responsáveis pela transferência de elétrons do NADPH para resazurina que resulta em resorufina e pico de absorção de comprimento de onda de $570 \mathrm{~nm}$ [34]. Os resultados são apresentados na Figura 7.

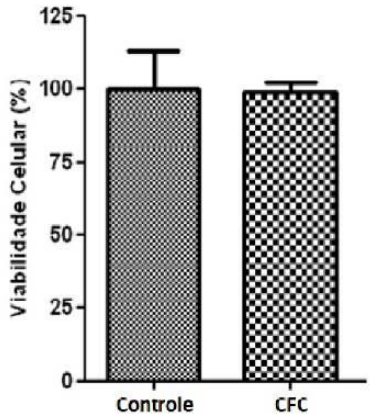

(A)

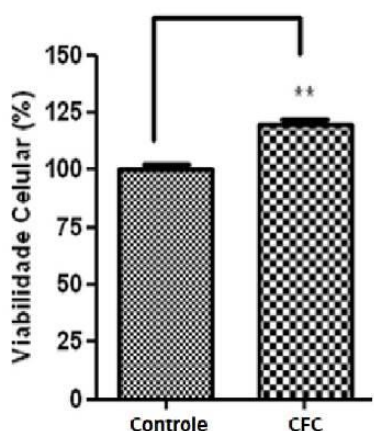

(B)

Figura 7: Resultado do ensaio de citotoxicidade na presença das bactérias S. aureus (A) e E.coli (B).

A Figura 7A mostra a viabilidade celular da cepa $S$. aureus após 24 h em exposição com o extrato do CFC (99,18 $\pm 5,8 \%)$, observamos a manutenção da viabilidade celular em relação ao controle-salina (100,0 $\pm 23, p>0,05)$. Esses dados corroboram com os estudos conduzidos por SHIEH et al. [35] que mostraram a inefetividade do cimento de fosfato de cálcio em cultura de $S$. aureus. No entanto, observamos aumento significativo da viabilidade celular da $E$. coli na presença do CFC $(119,6 \pm 4,4 \%, p<0,01)$ quando comparado com o controle-salina $(100,0 \pm 4 \%)$, após 24 h. O corante resazurina é considerado um indicador de função mitocondrial, uma vez que é metabolizado pelas enzimas celulares como as redutases presentes nas mitocôndrias [36]. De acordo com KAMITAKAHARA et al. [37] , a hidroxiapatita favorece adesão e aumento da atividade metabólica da bactéria $E$. coli. Assim, os resultados do presente trabalho corroboram com os dados da literatura sobre o possível efeito não citotóxico dos cimentos de fosfato de cálcio estudados.

\subsection{Ensaio in vivo HET-CAM}

$\mathrm{O}$ ensaio de contato direto do biocimento à membrana córion-alantoide (HET-CAM) é baseado no método alternativo à experimentação animal para testar materiais irritantes corrosivos e/ou severos. Para o ensaio, a solução fisiológica a $0,9 \%$ foi usada como controle negativo e ao ser aplicada sobre a membrana não apresentou resposta visual quanto às alterações fisiológicas; assim, esta solução é classificada como não irritante (ver imagens de controle positivo na figura 8a). A solução de $\mathrm{NaOH} 1 \mathrm{M}$ foi usada como controle positivo, após ser aplicada sobre a membrana observou-se uma hemorragia grave (ver imagens de controle negativo na figura 8e). O CFC foi colocado em contato com a membrana por 30, 120 e 300 segundos, imagens $8 \mathrm{~b}, 8 \mathrm{c}$ e $8 \mathrm{~d}$, respectivamente.

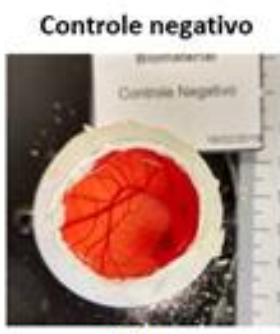

(a)

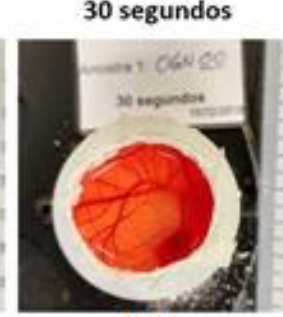

(b)

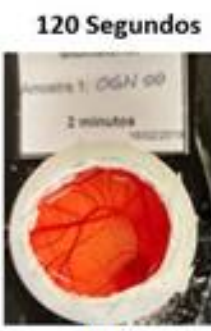

(c)

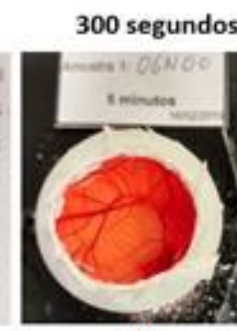

(d)

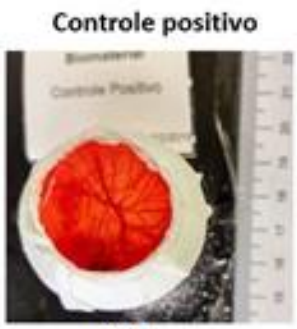

(e)

Figura 8: Ovos controle positivo, negativo e após diferentes tempos de contato com o material avaliado. 
Os escores alcançados pelas amostras testadas e sua classificação quanto ao potencial de irritação foram representados na tabela 4.

Tabela 4: Escores e classificação do biomaterial testado

\begin{tabular}{l|l|l}
\hline AMOSTRA & ESCORE & CLASSIFICAÇÃO \\
\hline (C+) SOLUÇÃO SALINA & 0 & NÃO IRRITANTE (NI) \\
(C -) SOLUÇÃO DE HIDRÓXIDO DE SÓDIO 0,1 N & 9 & IRRITANTE SEVERO (IS) \\
CFC & 0 & NÃO IRRITANTE (NI) \\
\hline
\end{tabular}

De acordo com os resultados, após o contato do CFC com a membrana não foram observadas reações ou alterações nas membranas córion-alantoide dos ovos embrionados, em todos os tempos analisados, sendo o escore 0 (zero) e, portanto, classificado como não irritante (Tabela 4). O resultado apresentado pelo biocimento sugere que o material é biocompatível.

\subsection{Ensaio de degradação}

Os CPCs podem ser degradados por reabsorção ativa ou passiva. A reabsorção ativa é um processo celular mediado por osteoclastos, enquanto a reabsorção passiva é baseada na solubilidade química do material CPC. A introdução de uma adequada (macro) porosidade e interconectividade dos poros no CPC favorecerá o fluxo de fluidos, bem como a penetração celular, e, como consequência, acelerará sua degradação [38]. Os resultados do ensaio de degradação estão representados na figura 9.

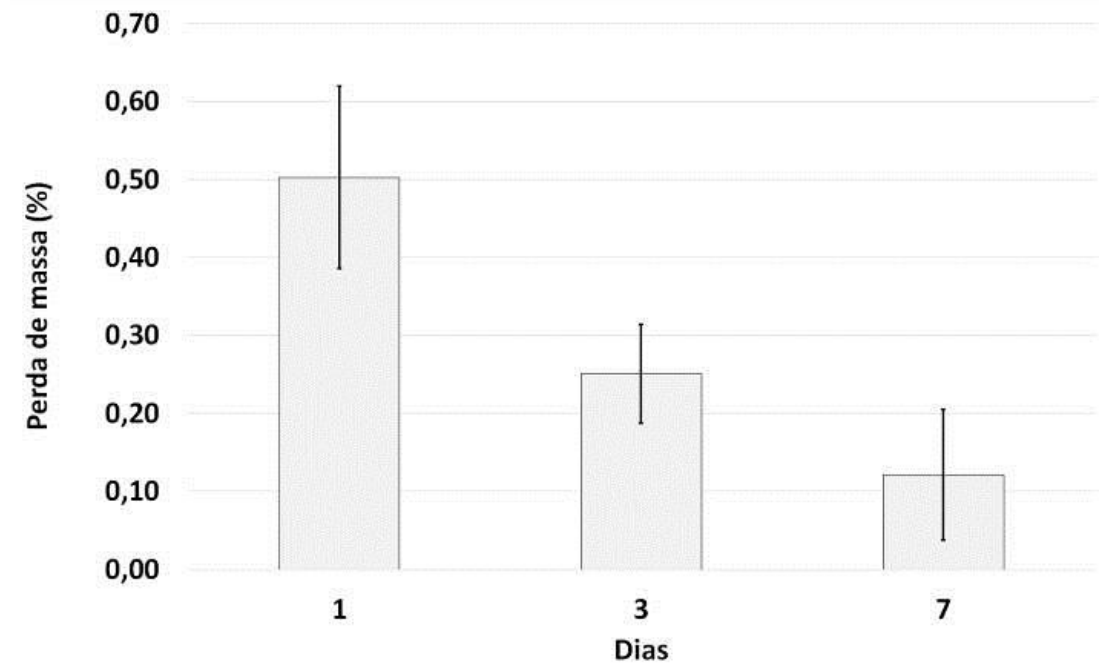

Figura 9: Resultados de perda de massa do material

A figura 9 mostra o perfil da perda de massa do biocimento imerso em solução Tris- $\mathrm{HCl}(\mathrm{pH} 7,4)$ por 7 dias. Após as primeiras 24 horas, observamos maior perda de massa do biocimento com valores de $0,5 \%$ seguido de redução dessa porcentagem ao longo do ensaio. O gráfico mostra redução da porcentagem de perda do biocimento após $3(0,25 \%)$ e $7(0,12 \%)$ dias de imersão na solução. De acordo com SOLENENCO et al [24] quando amostras de hidroxiapatita são imersas em solução tampão Tris- $\mathrm{HCl}$ por longo período as concentrações de cálcio e fosfato em solução apresentam um processo de dissolução na primeira fase seguido de aumento do pH. SOLENENCO et al [24] descreve que após um período do ensaio ocorre alterações das concentrações desses íons e supersaturação da solução que resulta em um processo secundário de cristalização que pode direcionar o sistema à uma diminuição da perda de massa da fase sólida para líquida.

A perda de massa após 1 dia de ensaio foi de $0,5 \%$, após três dias de imersão no Tris- $\mathrm{HCl}$ as três amostras apresentam redução no percentual de perda de massa, sendo 0,25\% em 3 dias e 0,12\% após 7 dias. Ao analisar todo o período de ensaio pode-se perceber que à medida que as amostras ficam mais tempo imersas a perda de massa reduz, o que pode ser indicativo de uma reprecipitação de material. SOLENENCO et al. [24] em seu estudo afirma que pode acontecer um processo secundário de precipitação de apatitas durante imersão de composto de hidroxiapatita em Tris-HCL. 


\section{CONCLUSÕES}

Como resultado do processamento do biocimento de fosfato de cálcio bifásico com $3,2 \% \mathrm{~m} / \mathrm{m}$ de CMC (agente ligante) e utilização de uma solução aquosa mais enriquecida de fosfato de sódio (concentração de 5\%), observou-se redução de 33,6\% no tempo inicial de pega e de 38,7\% no tempo final de pega do material nanométrico em relação ao micrométrico. Porém, os tempos de pega ficaram acima do adequado para aplicação clínica.

Os ensaios de resistência a flexão mostraram que o material nanométrico apresentou resistência a tração na flexão de 3,89Mpa, dentro da faixa de resistência do osso esponjoso. O ensaio de ultramicrodureza mostrou que o módulo de elasticidade do material foi $46 \%$ maior que do osso esponjoso. Isso indica que conseguiu-se adequar a resistência a flexão do material, porém são necessários mais estudos para adequar o módulo de elasticidade do biocimento, a fim de que seja indicado para uso clínico.

Os resultados de citotoxicidade evidenciaram que o cimento nanométrico não interferiu significativamente na viabilidade celular das bactérias testadas, o que sugere que o material não seja citotóxico. Após a avaliação pelo ensaio HET-CAM, o material foi classificado como não irritante, também sugerindo boa biocompatibilidade. Durante o ensaio de degradação a redução da perda de massa, aparentemente, foi causada pelo processo secundário de precipitação de apatitas na superfície das amostras.

\section{AGRADECIMENTOS}

Os autores agradecem a todos os pesquisadores, alunos de iniciação científica e funcionários que colaboraram para a execução deste trabalho. Também as instituições CEFET, CDTN, UFOP, INPE por disponibilizar o uso dos seus laboratórios para continuidade do estudo. A todos os componentes do Departamento de Engenharia de Materiais (DEMAT) do CEFET e a CAPES pelo fomento à pesquisa. A empresa Phosther Tecnologia de Aglomerações Ltda por disponibilizar o fosfato de cálcio usado neste estudo.

\section{BIBLIOGRAFIA}

[1] HENCH, L. L., WILSON, J., An introduction to Bioceramics, 2 ed., Singapore, River Edge, New Jersey, United States of America, World Scientific Publishing Co., 1993.

[2] O’NEILL, R., MCCARTHY, H.O., MONTUFAR, E.B., et al., "Critical review: Injectability of calcium phosphate pastes and cements", Acta Biomaterialia, v.50, issue 1, pp. 1-19, Mar. 2017.

[3] FRANCZAK, P. F. Síntese e caracterização de biocimentos de fosfatos de cálcio para uso na reparação do tecido ósseo, Dissertação de Mestrado, Universidade do Estado de Santa Catarina, Joinville, Set. 2014.

[4] PALMER, I., NELSON, J., SCHATTON, W., et al., "Biocompatibility of calcium phosphate bone cement with optimized mechanical properties", Journal of biomedical materials research b: applied biomaterials, v. 104B, issue 2, pp. 308-315, feb. 2016.

[5] GINEBRA, M., MONTUFAR, E. B. "Cements as bone repair materials". In: Pawelec, K. M., Planell, J. A., Bone Repair Biomaterials, Regeneration and Clinical Applications, 2 ed., chapter 9, Woodhead Publishing Series in Biomaterials, 2019.

[6] CANAL, C., GINEBRA, M.P. "Fiber-reinforced calcium phosphate cements: A review", Journal of the mechanical behavior of biomedical materials, v. 4, pp. 1658-1671, 2011.

[7] ELIAZ, N., METOKI N. "Calcium Phosphate Bioceramics: A Review of Their History, Structure, Properties, Coating Technologies and Biomedical Applications”, Materials, v. 10, issue 4, Mar. 2017.

[8] SILVA, L. A. Desenvolvimento de cimento de fosfato de cálcio reforçado com fibras para uso na área médico-odontológica, Tese de Doutorado, Universidade de Campinas, Campinas, 2002.

[9] WANG, S., ZHANG, S., WANG, Y., et al., "Reduced graphene oxide/carbon nanotubes reinforced calcium phosphate cement", Ceramics International, v. 43, n. 16, pp. 13083-13088, Nov. 2017.

[10] AJAXON, I., ACCIAIOLI, A., LIONELLO, G., et al., "Elastic properties and strain-to-crack-initiation of calcium phosphate bone cements: Revelations of a high-resolution measurement technique", Journal of the Mechanical Behavior of Biomedical Materials v. 74, pp. 428-437, Oct. 2017.

[11] JANSEN, J., OOMS, E., VERDONSCHOT, N., et al., "Injectable calcium phosphate cement for bone repair and implant fixation", The Orthopedic Clinics of North America, v. 36, issue 1, pp. 89-95 Jan. 2005.

[12] GINEBRA, M.P., FERNANDEZ, E., De MAEYERL, E,A,P, et al., "Setting Reaction and Hardening of an Apatitic Calcium Phosphate Cement", Journal of Dental Research, v. 76, issue 4, pp. 905-912, Apr. 1997. 
[13] AlBuQuerQue, J. S. V., ALVES, E. R., NOGUEIRA, R. E. F. Q. “Análise Estatística do tempo de Pega de Biocimentos de Fosfato de Cálcio", In: Anais do Congresso latino americano de órgãos artificiais e biomateriais, Natal, 2012.

[14] DRIESSENS, F. C. M., BOLTONG, M. G., DE MAEYER, E. A. P. , et al., "Effect of temperature and immersion on the setting of some calcium phosphate cements", Journal of materials science: materials in medicine, v. 11, issue 7, pp. 453-457, Jul. 2000.

[15] JIA, J., ZHOU, H., WEI, J., et al., "Development of magnesium calcium phosphate biocement for bone regeneration”, Journal of the Royal Society Interface, v. 7, n. 49, pp. 1171-1180, Apr. 2010.

[16] BAUDÍN, C., BENET, T., PENA, P. "Effect of graphene on setting and mechanical behavior of tricalcium phosphate bioactive cements", Journal of the Mechanical Behavior of Biomedical Materials, v. 89, pp. 33-47, Jan. 2019.

[17] ASSOCIAÇÃO BRASILEIRA DE NORMAS TÉCNICAS, NBR 12128. “Gesso para construção civil Determinação das propriedades físicas da pasta de gesso", 2017.

[18] BERTOL, L. S., ESCOBAR, C. F., KINDLEIN JÚNIOR, W., et al., "Projeto, fabricação e avaliação de implantes craniofaciais personalizados: proposta de utilização de materiais combinados”, Rev. Bras. Eng. Biom., v. 26, n. 2, pp. 79-89, Ago. 2010.

[19] BOEHM, A. V., MEININGER, S., TESCH, A., et al., "The Mechanical Properties of Biocompatible Apatite Bone Cement Reinforced with Chemically Activated Carbon Fibers", Materials, v. 11, issue 2, n. 192, pp. 1-12, Feb, 2018.

[20] ANTUNES, J. M. A. A indentação de materiais maciços e filmes finos: Modelação e análise inversa, Tese de Doutorado, Universidade de Coimbra Faculdade de Ciências e Tecnologia, Coimbra, 2006.

[21] LUEPKE, N. P., KEMPER, F. H. "The het-cam test: an alternative to the Draize eye test", Fd Chem. Toxic., v. 24, n. 6/7, pp. 495-496, 1986.

[22] CAZEDEY, E.C.L., CARVALHO, F.C., FIORENTINO, F.A.M., et al., "Corrositex ${ }^{\circledR}$, BCOP and HETCAM as alternative methods to animal experimentation", Brazilian Journal of Pharmaceutical Sciences, v. 45, n. 4, pp. 759-766, Oct./Dec., 2009.

[23] AMERICAN SOCIETY FOR TESTING AND MATERIALS STANDARD, ASTM C1161 - 18. “Test Method for Flexural Strength of Advanced Ceramics at Ambient Temperature", 2018.

[24] SOlONENKO, A. P., BLESMAN, A. I., POLONYANKIN, D. A. "Preparation and in vitro apatiteforming ability of hydroxyapatite and $\beta$-wollastonite composite materials", Ceramics International, v.44, issue 15, pp.17824-17834, Oct. 2018.

[25] DING, Y., TANG, S., YU, B., et al., "In vitro degradability, bioactivity and primary cell responses to bone cements containing mesoporous magnesium-calcium silicate and calcium sulfate for bone regeneration", J. R. Soc. Interface, v.12, issue 111, Oct. 2015.

[26] WANG, Q., WANG, Q, WAN, V. "The effect of porosity on the structure and properties of calcium polyphosphate bioceramics”, Ceramics - Silikáty, v.55, issue 1, pp.43-48, 2011.

[27] DRIESSENS, F. C. M., FERNÁNDEZ, E., GINEBRA, M. P., et al., "Calcium phosphates and ceramic bone cements vs. acrylic cements”, Anal. Quim. Int. Ed., v. 93, pp. S38 - S43, 1997.

[28] RAMALHO, A. C. A. Desenvolvimento e caracterização de cimentos ósseos inovadores, Dissertação de Mestrado, Faculdade das Ciências da Saúde, Universidade da Beira Interior, 2010.

[29] WANG, X., YE, J., WANG, Y., et al., "Control of crystallinity of hydrated products in a calcium phosphate bone cement", Journal of Biomedical Materials Research Part A, v. 81, issue 4, pp. 781-790, Jun. 2007.

[30] LOPEZ-HEREDIA, M. A., KAMPHUIS, G. J. B., THÜNE, P. C., et al., "An injectable calcium phosphate cement for the local delivery of paclitaxel to bone", Biomaterials, v. 32, issue 23, pp. 5411-5416, Aug. 2011.

[31] CHANG, Y.T., CHEN, C.M., TU, M.Y., et al., "Effects of osteoporosis and nutrition supplements on structures and nanomechanical properties of bone tissue", J. Mech. Behav. Biomed. Mater, v.4, issue 7, pp. 1412-1420, Oct.,2011.

[32] ORÉFICE, R. L., PEREIRA. M. de M., MANSUR, H. S. Biomateriais: Fundamentos \& Aplicações, 1.ed., 1.reimpr., Rio de Janeiro, Cultura Médica: Guanabara Koogan, 2012.

[33] GARCIA, A., SPIM, J. A., SANTOS C. A. "Ensaio de dureza”. In: Ensaio de materiais, 2. Ed, capítulo 4, Rio de Janeiro, LTC, 2015. 
[34] MUNSHI, S., TWINING, R. C., DAHL, R. "Alamar blue reagent interacts with cell-culture media giving different fluorescence over time: Potential for false positives", Journal of Pharmacological and Toxicological Methods, v. 70, issue 2, pp. 195-198, Sep. - Oct. 2014.

[35] SHIEH, T.M., HSU, S.H., CHANG, K.C., et al., "Calcium Phosphate Cement with Antimicrobial Properties and Radiopacity as an Endodontic Material”, Materials, v. 10, issue 11, pp. 1256-1272, 2017.

[36] RAMPERSAD, S.N. "Multiple Applications of Alamar Blue as an Indicator of Metabolic Function and Cellular Health in Cell Viability Bioassays", Sensors, v. 12, issue 9, pp. 12347-12360, 2012.

[37] KAMITAKAHARA, M., TAKAHASHI, S., YOKOI, T., INOUE, C., IOKU, K.” Adhesion behaviors of Escherichia coli on hydroxyapatite”, Materials Science and Engineering C, v. 61, pp. 169-173, 2016.

[38] LANAO, R. P. F., LEEUWENBURGH, S. C. G., WOLKE, J. G. C., et al., "In vitro degradation rate of apatitic calcium phosphate cement with incorporated PLGA microspheres", Acta Biomaterialia, v. 7, issue 9, pp. 3459-3468, Sep. 2011.

\section{ORCID}

Marcelo Augusto Brito Madureira

Katia Michelle Freitas

Camila de Lima Cruz

Tércio Assunção Pedrosa

Rafael Lopes

Sidney Nicodemos da Silva

Danielle Marra de Freitas Silva Azevedo
https://orcid.org/0000-0003-0865-460X
https://orcid.org/0000-0002-4025-879X
https://orcid.org/0000-0002-7836-6972
https://orcid.org/0000-0002-0347-7221
https://orcid.org/0000-0003-1121-4074
https://orcid.org/0000-0002-4431-6651
https://orcid.org/0000-0001-6463-7842 